\title{
LISBOA - LIVRO DE BORDO: ENTRE OS ESPAÇOS DO DESEJO E AS MEMÓRIAS DO ESPAÇO
}

\author{
Sérgio Roberto Massagli ${ }^{1}$
}

RESUMO: Este artigo analisa as relações entre memória, desejo e espaço, com referência à cidade de Lisboa descrita por José Cardoso Pires em Lisboa - Livro de bordo. Vozes, olhares, memorações. Procuro verificar o problema da representabilidade dos espaços desmaterializados da pós-modernidade, seja em face da transformação dos lugares em não-lugares, seja pela erosão globalizante do mundo e a consequente impossibilidade de acessar o "real" de uma forma não mediatizada, isto é, através de uma mimesis "ontologicamente pura".

Palavras-chave: Memória - Desejo - Espaço - Representação

ABSTRACT: This paper examines the relationship between memory, desire and space, with reference to Lisbon as it is described by José Cardoso Pires in his book Lisboa Livro de bordo. Vozes, olhares, memorações. I aim to investigate the problem of the representability of postmodern dematerialized spaces, whether in face of the transformation of places into non-places, either by the erosion of the globalizing world and the consequent impossibility to access the "real" in an unmediated way, ie, through an "ontologically pure" mimesis.

Key-words: Memory - Desire - Space - Representation

O homem que cavalga longamente por terrenos selváticos sente o desejo de uma cidade. Finalmente, chega a Isidora, cidade onde os palácios têm escadas em caracol incrustadas de caracóis marinhos, onde se fabricam à perfeição binóculos e violinos, onde quando um estrangeiro está incerto entre duas mulheres sempre encontra uma terceira, onde as brigas de galo se degeneram em lutas sanguinosas entre os apostadores. Ele pensava em todas essas coisas quando desejava uma cidade. Isidora, portanto, é a cidade de seus sonhos, com uma diferença. A cidade sonhada o possuía jovem; em Isidora, chega em idade avançada. Na praça, há o murinho dos velhos que veem a juventude passar; ele está sentado ao lado deles. Os desejos agora são recordações. (Italo Calvino)

Quando era criança

Vivi, sem saber,

Só para hoje ter

Aquela lembrança.

É hoje que sinto

Aquilo que fui

Minha vida flui

Feita do que minto.

\footnotetext{
${ }^{1}$ Doutorando no Programa de Doutorado em Estudos Literários da Faculdade de Ciências e Letras de Araraquara (FCLAr) da UNESP.
} 
Mas nesta prisão,

Livro único, leio

O sorriso alheio

De quem fui então.

(Fernando Pessoa)

$\mathrm{Na}$ intersecção dos textos acima, entrevejo que o desejo é o palco do conflito entre a passagem do tempo, com seu inevitável rastro de esquecimento, e o assalto tardio da memória. Movidos pelo desejo, submergimos nas águas do esquecimento para, num momento posterior, através de um resgate mnemônico, recobrarmos o sentido do que fomos outrora. Trata-se de um movimento dialético necessário para que nos tornemos humanos. Nietzsche diz que é possível viver quase sem lembranças e viver feliz, como fazem os animais, mas é impossível viver sem esquecer (1983, p. 273-274). Os animais vivem sem lembrar, no domínio absoluto dos seus desejos primários, mas o que nos torna humanos é justamente a possibilidade de esquecer o que vivemos e a consequente necessidade de recordá-lo e contá-lo aos outros. Aliás, falamos tanto sobre nossas memórias somente porque elas já não existem, como afirma Pierre Nora (1997). E se já não existem, como ter a certeza de que um dia existiram de fato? Ou, como saber se existiram da maneira como delas nos lembramos? Some-se a isso o problema de seu registro, na tentativa de se evitar que, novamente, desapareçam sob o manto escuro e silencioso do esquecimento. O medo do esquecimento limita-se com o medo da morte, "morte é a curva na estrada/ morrer é apenas não ser visto" (PESSOA, 1995. p. 142) - em outras palavras, morrer significa não ser já lembrado. Não obstante nossa obsessão com a lembrança, e em que pese o mau gosto do trocadilho, esquecer é preciso, é absolutamente necessário para que a vida se abra à novidade, livre do fardo do passado. Afinal, assim como lembrar, esquecer também é condição para a constituição da identidade do eu, pois somos aquilo que recordamos e também o que decidimos esquecer.

Esquecer torna-se, logo, condição sine qua non daquele alheamento a que se refere Pessoa, o qual lhe permite ler o "sorriso alheio" de quem fora na infância. Esse distanciamento necessário ao mesmo tempo dilui a distinção entre a "realidade" e representação (artística) desse passado. Adormecido pelo desejo que lhe fazia viver esquecido de si, ou viver sem saber (como fazem os animais de Nietzsche), o eu-lírico, 
assim como o habitante da Isidora de Calvino, descobrem na idade avançada que os desejos agora são recordações.

Essa convivência paradoxal entre memória e esquecimento aflige o indivíduo com a sua história pessoal, bem com o coletivo e sua identidade cultural. Nos últimos anos, os estudos sobre a memória cultural têm ganhado importância e pertinência na esfera acadêmica, especialmente se considerarmos que com o colapso dos estados-nação, a memória como forma de identidade de um grupo social também se fragiliza. A idéia de um fim da história (FUKUYAMA, 1992), ancorada no processo avassalador de globalização da economia, com a respectiva homogeneização cultural, torna mais do que nunca indispensável repensar o papel da memória e o seu lugar nas reflexões teóricas.

Hoje há que se fazer um esforço em espacializar a memória, mapeando materiais que por longo tempo foram negligenciados e que se constituem em lugares da memória inscritos na paisagem urbana, contando histórias outras, que não constam dos relatos oficiais, embora dialoguem com eles e mesmo o subvertam. No caso de Lisboa, Livro de Bordo, vozes, olhares, memorações (1997), de José Cardoso Pires, vamos encontrar nas pedras da calçada, nos azulejos das fachadas, nas estátuas as inscrições de uma memória tatuada na pele da cidade, a contar a história de outras Lisboas - Lisboas invisíveis, filtrada pela memória pessoal do escritor, num texto escrito em estilo refinado, que

oscila entre a procura duma semiótica da cidade-texto, desmedida no seu alcance quase ontológico, e o cepticismo profundo da legibilidade da cidade actualmente visível, originando um inventário provisório de Lisboas, "cidades que em nós se fazem" (L: 83), através de arte, música e literatura. (GROSSEGUESSE, 2009a)

O texto de Cardoso Pires materializa uma busca pelo emblema da grande cidade moderna onde o novo e o antigo, o presente e a memória convivem perante o brutal processo de desrealização do espaço urbano, seja pela emancipação de espaços considerados periféricos, subúrbios e cidades-satélite, que entram em simbiose com a organização pseudo-urbana de "CiberCity" (BOYER, 2004, p. 45), ou perante a desertificação e/ou musealização de centros urbanos históricos, tornados progressivamente em não-lugares. Pires começa seu texto logo advertindo o leitor para o perigo do olhar desfocalizador dos videosturistas: olhar a partir de miradouros, que 
apreende a paisagem na sua totalidade como "cenário de catálogo", como "frase feita", bem como avisa que não basta enfronhar-se na cidade em city tours sob a orientação de catecismos turísticos (PIRES, 1998, p. 10-11).

Lisboa, como outras cidades, tem se transformado em espaços urbanos de não-lugar. Tem com a "cidade branca" o mesmo fenômeno que marcou as grandes cidades nessas últimas duas décadas, que alguns autores chamam de "culturalização" (MEYER, 1999) ou "musealização" (HUYSSEN, 2000), que se iniciam por uma patrimonialização ou museificação de seus espaços, principalmente os espaços centrais, ditos históricos, sempre visando uma revitalização urbana que possibilitaria uma efetiva inserção dessas cidades dentro de um circuito global de cidades "culturais ou turísticas".

Podem-se entrever nessa "revitalização" de espaços antigos da cidade duas tentativas de conferir uma visibilidade excessiva que resultam em sua "espetacularização" (DEBORD, 1967), que seria resultante da evolução das estruturas socioeconômicas pós-industriais mundiais, que também teriam influência no próprio conceito de cultura contemporânea (JAMESON, 2002; HARVEY, 2003). Ironicamente, essa tentativa de dar visibilidade levada a cabo pela pós-modernidade acaba gerando um efeito contrário: a criação de não-lugares (AUGÉ, 1995), seja através da sua musealização (cidade-museu) seja, por outro lado, pela sua pasteurização através de sua modernização (cidade-pastiche).

Em ambos os casos, estamos diante de um processo de criação de um conceito de não-cidade: cidades-disneylândia que se tornam centros reificados pela indústria do "turismo cultural". Ambas as vias, a de preservar o antigo ou de construir o novo, resultam dessa mesma tentativa de espetacularização, cujas intenções são quase sempre mercantilizadoras. Daí os "catecismos turísticos" e suas leituras apoiadas em clichês, estereótipos e frases feitas. Roteiros à la carte para atender aos gostos dos peregrinos da indústria turísticas, que Pires viu amiúde por Lisboa:

Há eruditos em trânsito que praticam as vias sacras dos monumentos para ficarem de bem com a consciência cultural, vi disso aos montes; há os romeiros da dança tarântula, Alfama abaixo, Moraria acima, por amor aos labirintos de roteiro; há os viajantes de museu para os quais este mundo tem de andar sempre muito bem datado e arrumadinho; há de tudo. (PIRES, 1998, p.11) 


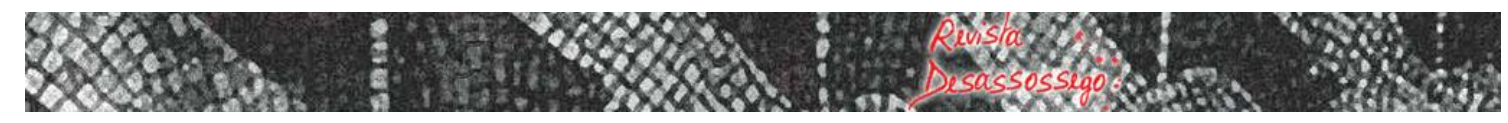

Há outra ambigüidade nessa busca de conferir visibilidade às cidades: na ansiedade em marcar, identificar a cidade com uma identidade singular, e vendê-la como uma mercadoria dotada de uma cultura própria, a indústria do turismo, que tem como alvo um mercado globalizado, faz com que ao final cidades com culturas distintas se assemelhem cada vez mais. Suas particularidades são enfatizadas por mensagens publicitárias que marcariam um lugar singular no competitivo mercado internacional, onde cidades do mundo todo disputam turistas e investimentos estrangeiros. Para tal fim, cedem a modelos homogeinizadores, impostos por grandes financiadores que visam o turista internacional e exigem um tipo de espaço orientado por um padrão global. Ou seja, essas cidades, ao tornarem-se espaços de fluxo, tornam-se "nãolugares". Como os shopping-centers, as vias aéreas, ferrovias, rodovias, as grandes cadeias de hotéis, os parques temáticos, os espaços midiáticos, tornam-se também espaços movediços, transitórios, que são ao mesmo tempo algum lugar e lugar nenhum. (AUGÉ, 2005, p. 12). Vários pensadores pós-modernos têm denunciado o caráter alienante e uniformizador da cultura-econômica, a sua tendência à superficialidade e ao pastiche cultural.

Com a globalização, a cultura teria perdido, de uma só vez, suas características antagônicas de singularidade e de universalidade. A globalização dos mercados implica uma concorrência entre todos os produtores mundiais de bens culturais, tendendo para a produção de uma cultura globalizada, ou seja, uniformizada pela cultura dominante mundialmente.

Essa cultura globalizada poderia ser vista como um simulacro (BAUDRILLARD, 1991) da própria noção de cultura, pura representação e imagem de si mesma. A preservação do patrimônio cultural urbano passa a ter de, ao mesmo tempo, manter a especificidade cultural local e se manter dentro de um padrão global, visando ao turismo internacional - o que provoca uma estandardização das áreas urbanas preservadas, uma dissolução da especificidade local em prol da padronização de imagens turísticas para serem consumidas globalmente.

É justamente essa visibilidade excessiva que, segundo Pires, ofusca e prejudica uma percepção do que constitui o corpo inteiro da cidade com seus outros sentidos, como seus cheiros:

...o do peixe de sal e barrica nas lojas da Rua do Arsenal, não vamos mais longe; o da maresia a certas horas das docas do 
Tejo, o do verão nocturno dos ajardinados da Lapa; os do armazéns de prestos marítimos entre Santos e o Cais do Sodré; o do peixe a grelhar em fogueiras à porta dos tascos de recanto ou de travessa, desde o Bairro Alto a Carnide; há, no inverno pelas ruas, o cheiro fumegante das castanhas a assar nos fogareiros dos vendedores ambulantes." (PIRES, 1998, p.12)

e seus sons, sua vozes, “... acima de tudo há a voz e o humor, o tom e a sintaxe, aquilo que te está, cidade, no mais íntimo" (PIRES, 1998, p.12). Enfim, traços que da distância do miradouro ("nesta vista tirada do Castelo de São Jorge") se ocultam pela distância, do alheamento que faz com que não se vinculem à imagem seus sons e cheiros mais íntimos, impedindo que se crie aquela "cumplicidade com a imagem, com os saberes, os gostos e os defeitos dum mundo tão privado" (PIRES, 1998, p.13) sem a qual não é possível perceber o genius loci de Lisboa.

Afastando-se do "visual imediato" e das "panorâmicas e vistas gerais", a que ele se refere como "frases feitas ou cenários de catálogo", entrega-se a sua navegação em busca das "vozes e cheiros" que se constituem em "registros inconfundíveis do espírito do lugar" (PIRES, 1998, p. 12). Como diz a certa altura: "Ninguém poderá conhecer uma cidade se não a souber interrogar, interrogando-se a si mesmo. Ou seja, se não tentar por conta própria os acasos que a tornam imprevisível e lhe dão o mistério da unidade mais dela" (PIRES, 1998, p. 11). Esta "instrução" de leitura, conforme aponta Izabel Margato (1999), é pré-condição para uma reconstrução daquele espaço liminal onde o sujeito que conhece encontra-se com o objeto de seu questionamento.

Entretanto, o que está proposto por José Cardoso Pires é uma “dupla interrogação" necessária para que esse encontro se efetive, pois o processo de conhecimento só poderá resultar dessa interação, desse "encontro que se constrói com os acasos, os indícios, os signos capazes de revelar o mistério das cidades.” Assim, nos vãos entre desejo e memória, presente e passado, entre o eu (l'écrivain-flanêur) e o outro (a cidade) revela-se o intento principal do autor: denunciar o estado desabitado da Lisboa atual e recuperá-la como "um 'lieu identitaire, relationnel et historique' (AUGÉ, 1992, p. 100) no espaço bidimensional do livro." 2

\footnotetext{
2 Estátuas, bichos e velhos - a Lisboa carnavalizada: de Alexandre O’Neill a José Cardoso Pires. In: Cidade e Modernidade na literatura (coord. Volker Jaeckel), Actas da Secção do $8^{\circ}$ Congresso da Associação Alemã de Lusitanistas (LMU, Munique, 2009), UFMG / FALE, no prelo.
} 


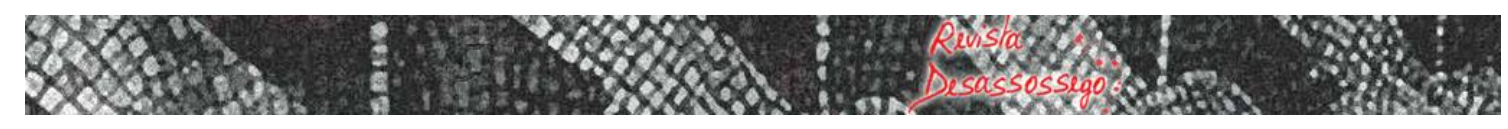

Cardoso Pires, ao preferir falar da cidade a partir de uma perspectiva marginal, refuta as leituras que se fazem da cidade: ora monumentais, ora panorâmicas, sempre voltadas para a institucionalização do passado ou para a legitimação de objetivos econômicos. Ao se posicionar "um tanto à margem" face a "tu cidade desfocada" deixa claro que o que está em jogo é uma leitura da cidade que "diz respeito menos à compreensão da sua totalidade do que ao mergulho no seu cotidiano e no complexo de suas estranhezas que se "contrapõem ao visível e facilmente 'legivel" (SILVA, p. 144). Essas estranhezas são os registros acústicos e olfativos que contribuem para anular outro alheamento (neste caso seria melhor o termo alienação) provocado pela leitura do visual imediato que, no caso de Lisboa, não se deve à modernidade da grande cidade, mas sobretudo à configuração turística criticada por Cardoso Pires. O alheamento que o move é aquele que o motiva a escrever a (re)aprendizagem do lugar através da errância. $\mathrm{O}$ alheamento e o desejo de regresso ao lugar concedem-lhe essa posição privilegiada de

O tropeçar em recantos, desenhos e inscrições, que de improviso abrem a superfície do quotidiano para camadas subjacentes, evoca o choc, no entanto sem a componente do pavor, e não ao serviço da experiência da cidade moderna: agora, a atitude do flâneur obedece à missão de reabitar a cidade. (GROSSEGUESSE, 2009b)

O confronto entre o novo e o antigo poetizado em Baudelaire foi essencial para o pensamento benjaminiano do alheamento e do choc. Entretanto, para Cardoso Pires, o alheamento é outro: "de se tornar turista da sua própria cidade". (GROSSEGUESSE, 1997, p. 04).

A experiência do choque aqui não deve ser entendida somente como o mecanismo de assimilação dos eventos ao acervo das memórias conscientes, ou voluntárias, ${ }^{3}$ o que os anularia para vida poética, mas também como a experiência específica de recuperar fragmentos da mémoire involuntaire, definida por Marcel Proust. $\mathrm{O}$ ato da recuperação significa ao mesmo tempo a perda da sua virgindade devido à passagem destes fragmentos ao consciente. Segundo Benjamim, “o importante,

\footnotetext{
3 A memória voluntária estaria ligada à esfera da consciência desperta, da qual dependeria a proteção contra os estímulos externos, os chocs, sem a qual estes poderiam vir a causar efeitos traumáticos no indivíduo. Dessa forma, ao ampliar as situações em que o homem se confronta com os chocs, o tempo da grande indústria teria reforçado o âmbito da consciência e da memória voluntária restringindo as condições de florescimento da memória involuntária.
} 
para o autor que rememora, não é o que ele viveu, mas o tecido de sua rememoração, o trabalho de Penélope da reminiscência" (BENJAMIN, 1994, p. 37).

Desta maneira, mais do que indicar o reaparecimento de um conteúdo ou objeto, a memória é um movimento, uma ação, que fica mais problematizada na questão que Benjamin se coloca: "ou seria preferível falar do trabalho de Penélope do esquecimento?" (BENJAMIN, 1994, p. 37). Nesse ponto Benjamin já indica que a memória involuntária encontra-se mais próxima do esquecimento do que da lembrança. O esquecimento se faz necessário, pois o movimento engendrado pela memória é aquele que vai associar duas sensações diferentes, distantes no tempo e no espaço. É um movimento de analogias. Em vez de retomar o passado, a memória involuntária vai superá-lo, realizando o entrecruzamento dos tempos.

Michel De Certeau (1996) escreve que o que interessa à narrativa da cidade é revelar o que ela não mostra, aquilo que é invisível em seu cotidiano, procurar por seus sentidos perdidos ou ocultos, impossíveis de serem significados a partir de um olhar primeiro, panorâmico e contemplativo. Como diz Cardoso Pires, logo no início de seu "livro de bordo", acerca de Lisboa: " a distância inventa cidades, como muito bem sabemos. Por essa razão é que eu nunca me esqueço daquele aviso que alguém um dia deixou nesta varanda de curiosos: A Primeira Vista é Para os Cegos!, aviso sábio, sem dúvida ...” (PIRES, 1997, p. 11). Para conhecer as Lisboas invisíveis, Cardoso Pires se afasta da visibilidade ofuscante das paisagens encomendas da Ville Blanche para fazer um inventário dos lugares, com seus cheiros e sons, seus fantasmas a partir de uma tessitura entre desejos e memória de modo a diluir a distinção entre o exterior, a cidade, e o interior, a sua representação. Temos então a noção de cidade "trans-discursiva", que transgride a divisão que Foucault faz entre o plano discursivo (códigos) e nãodiscursivo (práticas) (SHIELDS, 1996, p. 246). Em outras palavras, entre a Lisboa "real", trilhada por Cardoso Pires e as cidades invisíveis que se vão se incorporando na paisagem, ao longo do tempo, deixando nela suas inscrições, vamos encontrar as cidades trans-discursivas em que o empírico e o inventado misturam-se, obliterando a distinção ente o real e o imaginado, entre o fatual e o fictício. 


\section{Referências bibliográficas}

AUGÉ, Marc - Não Lugares: Introdução a uma Antropologia da Sobremodernidade. Tradução: Miguel Serras Pereira. Lisboa: 90 Graus Editora, 2005

BAUDRILLARD, Jean. Simulacros e simulação. Tradução: Maria João da Costa Pereira Lisboa: Relógio d'Água, 1991.

BENJAMIN, Walter. Charles Baudelaire um lírico no auge do capitalismo. In Obras escolhidas, Vol. 3. 3ª Ed. Tradução: José Carlos Martins Barbosa e Hemerson Alves Baptista São Paulo: Brasiliense, 1994.

A imagem de Proust. In Obras escolhidas, Vol. 3. Tradução: José Carlos

Martins Barbosa e Hemerson Alves Baptista São Paulo: Brasiliense, 1994.

BOYER, M. Christine, "The Imaginary Real World of CiberCity”, in: Rodolphe ElKhoury / Edward Robbins (orgs.), Shaping the City: Studies in history, theory and urban design, New York: Routledge, 2004, pp. 231-251.

. The City of Collective Memory, Cambridge, 1994.

CALVINO, Ítalo. As cidades invisíveis. Tradução: Diogo Mainardi. São Paulo: Cia. das Letras, 1990.

CERTEAU, Michel e GIARD, Luce: A invenção do Cotidiano: 2. Morar e Cozinhar. Tradução: Ephraim Ferreira Alves Petrópolis; Rio de Janeiro, Ed. Vozes, 1996.

DEBORD, G. A sociedade do espetáculo. Tradução: Estela dos Santos Abreu. Rio de Janeiro: Contraponto, 1967.

FUKYAMA, Francis. O Fim da história e o último homem. RJ: Rocco, 1992

GROSSEGUESSE, Orlando. Cidades que em nós se fazem. Lisboa-Livro de bordo de José Cardoso Pires como "entre-lugar”, [XI' Congresso ABRALIC, São Paulo, 14 de Julho de 2008], FronteiraZ. Revista digital do grupo de pesquisa «O Narrador e as Fronteiras do Relato, no 4 (Dez. 2009), São Paulo: PUC-SP.

. Estátuas, bichos e velhos - a Lisboa carnavalizada: de Alexandre O’Neill a José Cardoso Pires. In: Cidade e Modernidade na literatura (coord. Volker Jaeckel), Actas da Secção do $8^{\circ}$ Congresso da Associação Alemã de Lusitanistas (LMU, Munique, 2009), UFMG / FALE, no prelo.

HARVEY, David. Condição pós-moderna. Trad. Adail Sobral e Maria Estela. Gonçalves. 12a . ed. São Paulo: Loyola, 2003 
HUYSSEN, A. Seduzidos pela memória: arquitetura, monumentos, mídia. Trad. de Sérgio Alcides Rio de Janeiro: Aeroplano, 2000.

IZQUIERDO, Ivan. Memória. Porto Alegre: Artmed, 2002.

JAMESON, Frederic. Pós-Modernismo, ou, a lógica cultural do capitalismo tardio. 2 ed. Tradução: Maria Elisa Cevasco. São Paulo: Ática, 2002.

MARGATO, Isabel. A primeira vista é para os cegos. Revista Semear, nº 3, Rio de Janeiro: PUC, 1999, p. 37- 52

MEYER, H. City and Port. Urban planning as a cultural venture in London, Barcelona, New York and Rotterdam: changing relations between public urban space and largescale infrastructure. Rotterdam, International Books, 1999.

NIETZSCHE, F. Coleção Os Pensadores. Obras incompletas. $3^{\text {a }}$ ed. São Paulo: Abril Cultural, 1983.

NORA, Pierre. Les lieux de mémoire, Paris: Gallimard, 1997.

PESSOA, Fernando. Poesias. 15a. Ed. Lisboa: Ática, 1995

PIRES, José Cardoso. Lisboa Livro de bordo. Vozes, olhares, memorações. 4 ed., Lisboa: Dom Quixote, 1998.

SHIELDS, Rob. “A Guide to Urban Representation and What to do about it: Alternative Traditions of Urban Theory", in: Anthony D. King (org.), Re-Presenting the City. Ethnicity, Capital and Culture in the $21^{\text {st }}$ Century Metropolis, New York: NYU Press, 1996.

SILVA, Rodrigues da. Cidade, minha cúmplice [Entrevista com J. Cardoso Pires]. Jornal de Letras, Artes e Ideias, Lisboa, 19-11-1997, pp. 17-19. 